\title{
Effects of Vinyl Substitutions on Resonance Raman Spectra of (Bacterio)chlorophylls
}

\author{
Ute Feiler and Tony A. Mattioli \\ Section de Biophysique des Protéines et des Membranes, DBCM/CEA and URA 1290/CNRS, C.E. Saclay, 91191 Gif sur \\ Yvette Cedex, France
}

Ingrid Katheder and Hugo Scheer

Botanisches Institut der Universität, Menzinger Str. 67, D-80638 Munich, Germany

Marc Lutz and Bruno Robert*

Section de Biophysique des Protéines et des Membranes, DBCM/CEA and URA 1290/CNRS, C.E. Saclay, 91191 Gif sur Yvette Cedex, France

\begin{abstract}
Soret resonance and $Q_{y}$ preresonance Raman spectra are reported and compared for a series of (bacterio)chlorophylls. Chlorophyll $a$, 2-acetylchlorophyll $a$, bacteriochlorophyll $a$ and 2-vinylbacteriochlorophyll $a$ were studied in the non-protic solvent tetrahydrofuran. These experiments were designed to identify Raman bands corresponding to the stretching mode(s) of the vinyl group at the C-2 position of ring $I$ of chlorophyll $a$ and 2-vinylbacteriochlorophyll $a$, and to ascertain whether additional bands corresponding to $C_{a} C_{m}$ and/or $C_{b} C_{b}$ vibrations could be observed in the $1615-1660 \mathrm{~cm}^{-1}$ region. Raman spectra of chlorophyll $a$ and 2vinylbacteriochlorophyll $a$ exhibit a $1625 \mathrm{~cm}^{-1}$ band, which is absent from the Raman spectra of 2-acetylchlorophyll $a$ and bacteriochlorophyll $a$. It is assigned to the $v_{2 a} C_{2 b}$ mode of the vinyl group. No other band can be definitively assigned to any mode predominantly arising from vinyl motions. The acetyl-containing molecules 2-acetylchlorophyll $a$ and bacteriochlorophyll $a$ give rise to a $c a .1070 \mathrm{~cm}^{-1}$ band, which appears to be related to the presence of the acetyl substituent. The $1615-1660 \mathrm{~cm}^{-1}$ region of the Raman spectra of all four derivatives did not contain any additional band which could be ascribed to modes involving the $v C_{a} C_{m}$ and/or $\mathrm{vC}_{\mathrm{b}} \mathrm{C}_{\mathrm{b}}$ coordinates.
\end{abstract}

\section{INTRODUCTION}

In photosynthetic bacteria and plants, bacteriochlorophylls (BChl) and chlorophylls (Chl), respectively, ensure the capture of light energy and its conversion into chemical potential energy. These molecules are generally found as cofactors bound to proteins. Most of the (bacterio)chlorophyll-binding proteins are membrane proteins and, although $\mathrm{x}$-ray and electron crystallography have met with remarkable success in solving the structure of the reaction centre of purple bacteria ${ }^{1}$ and two antenna complex, ${ }^{2,3}$ our knowledge of the structure of the different binding sites of the chlorophylls is still too little to understand the mechanisms by which the proteic moiety influences the pigments properties. Most of the information on chlorophyll structure and environments in vivo is obtained by spectroscopic methods, coupled with chemical and biochemical methods. Resonance Raman (RR) spectroscopy has proved to be one of the most effective methods for obtaining very detailed information on chlorophyll states in their native environment (for reviews see Refs 4 and 5).

Raman spectra of (B)Chl molecules obtained at resonance all contain more than 50 distinct bands and extracting their structural information content requires precise assignment of these bands. Because of the large

* Author to whom correspondence should be addressed. size, complexity and low symmetry of the chlorophylls, these assignments are still far from comprehensive. Experimental data are still lacking, and only a few normal-mode calculations have been performed, using the QCFF/PI semi-empirical method.6,7 Only a few spectral regions have been used so far for characterizing the (B)Chl binding sites in proteins, i.e. a lowwavenumber region $\left(100-350 \mathrm{~cm}^{-1}\right)$, which contains bands sensitive to the $\mathrm{Mg}$ isotopes, ${ }^{8-10}$ and a highwavenumber region $\left(1600-1750 \mathrm{~cm}^{-1}\right)$. The latter region contains bands arising from the stretching modes of the conjugated carbonyl(s), ${ }^{11}$ which are sensitive to intermolecular interactions. ${ }^{4}$ It also contains a band at $c a .1610 \mathrm{~cm}^{-1}$, which aries from the stretching modes of methine bridges, ${ }^{1}$ and which is sensitive to the number of axial ligands on the central $\mathrm{Mg}$ atom of the molecule. ${ }^{12,13}$ Calculations performed by Donohoe et $\mathrm{al}^{7}$ and by Boldt et $a l^{6}$ predict, in addition to the 1610 $\mathrm{cm}^{-1}$ methine band, the possible activity, in the $1620-$ $1650 \mathrm{~cm}^{-1}$ range, of modes involving $\nu \mathrm{C}_{\mathrm{a}} \mathrm{C}_{\mathrm{m}}$ and $\nu C_{b} C_{b}$ internal coordinates in the RR spectra of both $\mathrm{BChl} a$ and Chl $a$. Resonance Raman experiments conducted on BChl $a$ at various excitations did not reveal any bands at these wavenumbers. ${ }^{4,14}$ However, preresonant Raman spectra of Chl $a$ excited at $1064 \mathrm{~nm}$ contained a $1625 \mathrm{~cm}^{-1}$ band, the assignment of which is not obvious. Chl a possesses a conjugated vinyl substituent on ring $\mathrm{I}$ at the $\mathrm{C}-2$ position, the $\mathrm{C}=\mathrm{C}$ stretching mode of which could account for this $1625 \mathrm{~cm}^{-1}$ band. Early Raman studies of Chl $a$ and of vinyl-containing chlorophylls at resonance with the Soret transition did 
not reveal any intense band which could primarily arise, in the $1600-1650 \mathrm{~cm}^{-1}$ region, from the stretching mode of the vinyl $\mathrm{C}=\mathrm{C}$ bond. ${ }^{15}$ Similarly, comparisons of Raman spectra obtained at Soret resonance from nickel methylpheophorbide $a$ and from nickel mesopyropheophorbide $a$ did not reveal any sizeable activity of the vinyl group. ${ }^{6}$ These observations did not agree with interpretations of the RR spectra of iron protoporphyrin IX, which ascribed a band at ca. $1620 \mathrm{~cm}^{-1}$ to the vinyl $\mathrm{C}=\mathrm{C}$ stretch. ${ }^{16}$ This discrepancy was ascribed to a markedly out-of-plane conformation of the vinyl group. $9,17,18$

It was therefore considered useful to readdress this problem. In this work, we compare resonance and preresonance Raman spectra of $\mathrm{Chl} a$ and 2-acetyl-Chl $a$ on the one hand and of BChl $a$ and 2-vinyl-BChl $a$ on the other. From these results we may conclude that (1) the $1625 \mathrm{~cm}^{-1}$ feature observed in the RR spectra of Chl $a$ is due to the presence of a vinyl group in this molecule, and thus that it should clearly involve the $v \mathrm{C}=\mathrm{C}$ coordinate of the vinyl group, and (2) no additional $\nu \mathrm{C}_{\mathrm{a}} \mathrm{C}_{\mathrm{m}^{-}}$and/or $\nu \mathrm{C}_{\mathrm{b}} \mathrm{C}_{\mathrm{b}}$-involving modes other than the $1610 \mathrm{~cm}^{-1}$ mode can be observed for either $\mathrm{Chl} a$ or $\mathrm{BChl} a$ in any of the resonance conditions we used. Each of these conclusions has consequences for the use of resonance Raman data of chlorophylls, i.e. (1) the presence of a $1625 \mathrm{~cm}^{-1}$ feature in an RR spectrum of a chlorophyll-containing sample may indicate the presence of a vinyl group on the chromophore and (2) the presence of a $1620-1640 \mathrm{~cm}^{-1}$ feature in RR spectra of $\mathrm{BChl} a$-containing samples unambiguously indicate the presence of hydrogen-bonded 2-acetyl carbonyl groups.

\section{EXPERIMENTAL}

\section{Sample preparation}

The pigments (Fig. 1) were prepared according to Smith and Calvin ${ }^{19}$ and Struck et al. ${ }^{20}$ For Raman experiments, the different pigments were dissolved in dry tetrahydrofuran (THF) at concentrations ranging from $10^{-4}$ to $10^{-3} \mathrm{M}$. In this polar, non-protic solvent, in this concentration range, it was shown that the (B)Chl remain monomeric, that the central $\mathrm{Mg}$ atom is hexacoordinated and that the different conjugated carbonyl groups are free from intermolecular interactions. ${ }^{9}$

\section{Raman spectroscopy}

Fourier transform (FT) Raman spectroscopy was carried out as described by Mattioli et al. ${ }^{14}$ using a Bruker FRA 106 Raman module coupled with an IFS 66 interferometer. Excitation radiation of $1064 \mathrm{~nm}$ was provided by a diode-pumped Nd:YAG laser. FTRaman spectra were recorded at room temperature with backscattering geometry. Liquid samples were held in a quartz tube. Each of the FT-Raman spectra presented is the result of the co-addition of 2000-10000 interferograms. Soret RR spectroscopy was carried out with a Jobin-Yvon $U 1000$ spectrometer equipped with a

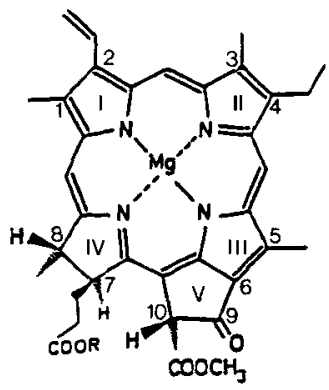

Chla

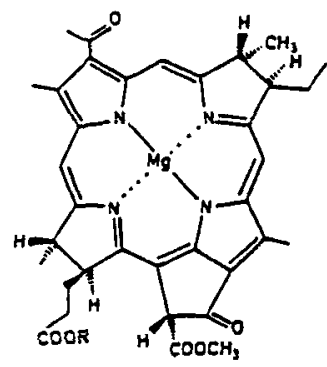

BChla

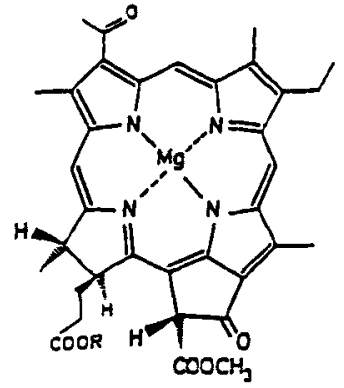

2-acetyl Chla

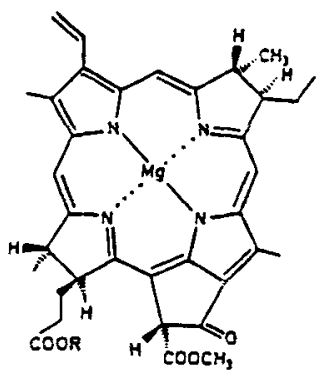

2-vinyl BChla
Figure 1. Molecular structures of chlorophyll $a, 2$-acetyl-chlorophyll $a$, bacteriochlorophyll $a$ and 2-vinylbacteriochlorophyll $a$.

charge-coupled device (CCD) detector. Resonance Raman spectra were obtained at low temperature ( $c a$. $77 \mathrm{~K}$ ) under conditions similar to those described by Robert and Lutz. ${ }^{21}$ Excitation radiation of $441.6 \mathrm{~nm}$ was provided by a $\mathrm{He}-\mathrm{Cd}$ continuous laser (Liconix). Resonance Raman spectra presented here are the results of 1-5 min exposure per spectral element.

\section{RESULTS AND DISCUSSION}

Figure 2 displays resonance Raman spectra (441.6 nm excitation) and FT-Raman spectra (1064 nm excitation) of $\mathrm{Chl} a$ (traces 1 and 3) and 2-acetyl-Chl $a$ (traces 2 and $4)$, all in the higher wavenumber range (1550-1750 $\mathrm{cm}^{-1}$ ). The FT-Raman spectrum of Chl a (trace 3) exhibits a distinct band at $1596 \mathrm{~cm}^{-1}$ arising from a methine bridge stretching mode; ${ }^{4}$ this low frequency indicates that the central $\mathrm{Mg}$ atom has two external ligands. ${ }^{13}$ Another band is present at above $1684 \mathrm{~cm}^{-1}$ in spectra 1 and 3, which arises from the stretching mode of the C-9-keto carbonyl group of Chl $a$. Its high frequency indicates that this group is free from any bonding interaction. Both of these bands are present in the FT-Raman spectrum of 2-acetyl-Chl a (trace 4), as expected. A band at $1624 \mathrm{~cm}^{-1}$, which is clearly active in the $1064 \mathrm{~nm}$-excited spectrum of Chl a (trace 3), is absent from the spectra of 2-acetyl-Chl $a$, and is replaced by a mode at $1660 \mathrm{~cm}^{-1}$ (trace 4). The latter band can be safely ascribed to the stretching mode of the 2-acetyl carbonyl group considering that the 2- 


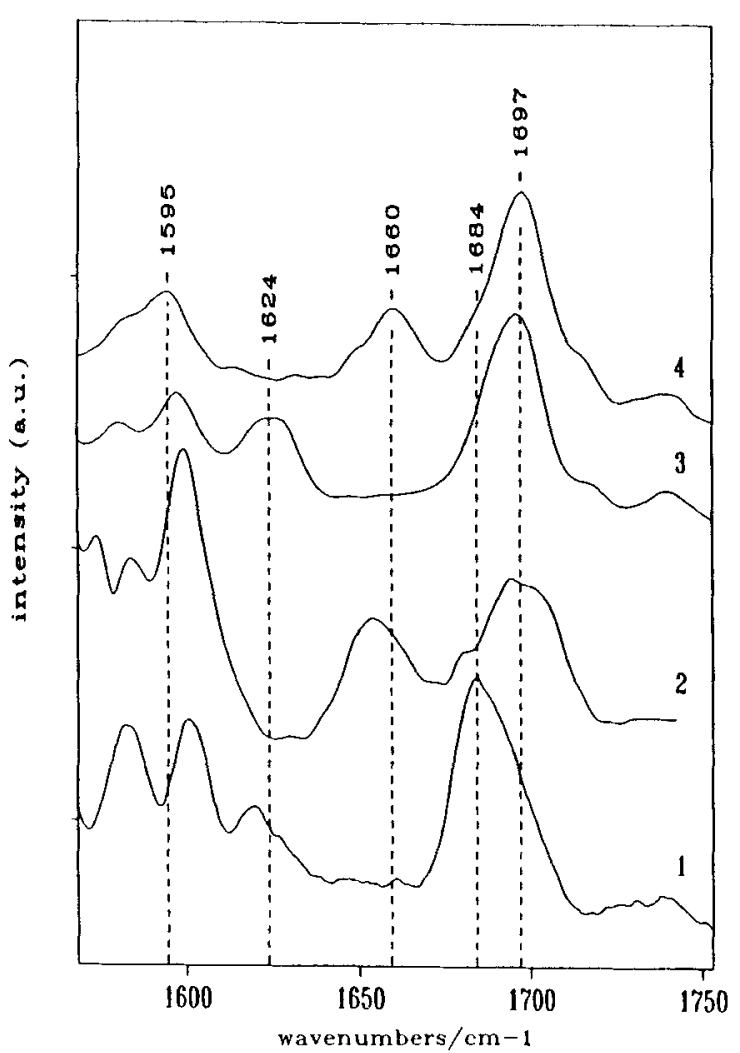

Figure 2. Resonance Raman spectra $\left(1580-1750 \mathrm{~cm}^{-1}\right)$ of Chl a ( 1 and 3 ) and 2-acetyl-Chl a (2 and 4) dissolved in THF, excited at 441.6 ( 1 and 2 ) and $1064 \mathrm{~nm}$ ( 3 and 4 ). Visible-excited RR spectra were recorded at $77 \mathrm{~K}$ and Raman spectra excited at 1064 $\mathrm{nm}$ were recorded at room temperature.

acetyl carbonyl stretching mode of $\mathrm{BChl} a$ is observed at this wavenumber. ${ }^{4}$ The FT-Raman spectrum of 2acetyl-Chl $a$ does not exhibit any observable contribution in the $1600-1660 \mathrm{~cm}^{-1}$ range that could be attributed to skeletal modes. At $441.6 \mathrm{~nm}$ excitation (Soret resonance), the same spectral features are conserved for each molecular species (traces 1 and 2), and the same differences are observable. It is worth noting that in resonance with the Soret transition, the intensity of the $1624 \mathrm{~cm}^{-1}$ band is lower relative to the 1600 $\mathrm{cm}^{-1}$ band intensity than in preresonance conditions with the $Q_{y}$ electronic transition (1064 $\mathrm{nm}$ excitation). At still shorter wavelength excitations $(413.1 \mathrm{~nm})$ the intensity of this mode is even lower and becomes barely observable (data not shown).

Figure 3 displays the high-wavenumber regions $\left(1550-1750 \mathrm{~cm}^{-1}\right)$ of the RR spectra of BChl $a$ (traces 1 and 3 ) and 2-vinyl-BChl $a$ (traces 2 and 4) obtained with 1064 and $363.8 \mathrm{~nm}$ excitation. In the BChl $a$ spectra, at both of these excitation wavelengths, the methine stretching band is observed at ca. $1595 \mathrm{~cm}^{-1}$ and, as already mentioned for $\mathrm{Chl} a$, there is no band in the $1600-1660 \mathrm{~cm}^{-1}$ range in these spectra which could be attributed to skeletal modes. As a result of temperature effects (work in progress), this band appears at ca. 1607 $\mathrm{cm}^{-1}$ in spectra 3 and 4. Two bands at 1659 and 1689 $\mathrm{cm}^{-1}$ arise from the stretching modes of the 2-acetyl and 9-keto groups, respectively. In the 2-vinyl-BChl $a$ spectra (traces 2 and 4), the $1660 \mathrm{~cm}^{-1}$ band is not observed, and is replaced by a mode at $1624 \mathrm{~cm}^{-1}$. It should also be noted that the presence of the vinyl

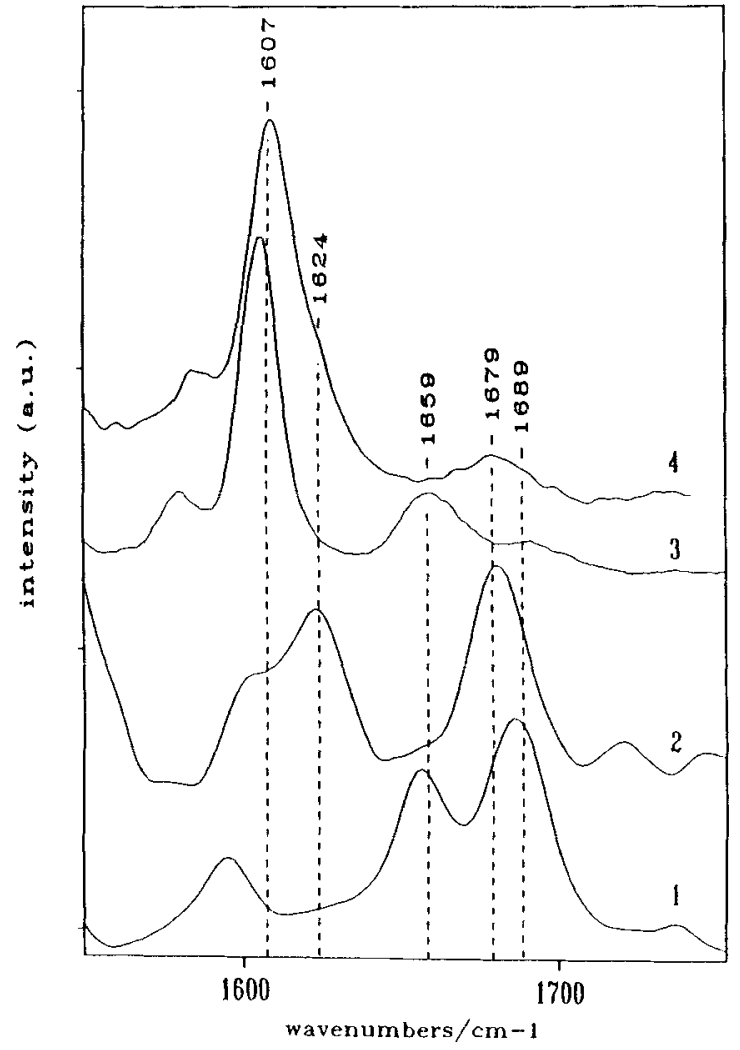

Figure 3. Resonance Raman spectra $\left(1580-1750 \mathrm{~cm}^{-1}\right)$ of $\mathrm{BChl}$ $a$ (1 and 3) and 2-vinyl-BChi a (2 and 4) dissolved in THF excited at $1064 \mathrm{~nm}(1$ and 2 ) and $363.8 \mathrm{~nm}$ ( 3 and 4 ). UV-excited $\mathrm{RR}$ spectra were recorded at $77 \mathrm{~K}$ and Raman spectra excited at $1064 \mathrm{~nm}$ were recorded at room temperature.

group (or the removal of the 2-acetyl group) is accompanied by a $10 \mathrm{~cm}^{-1}$ downshift of the wavenumber of the stretching mode of the 9-keto carbonyl group from ca. 1689 to $1679 \mathrm{~cm}^{-1}$. As for Chl $a$, the $1624 \mathrm{~cm}^{-1}$ band is stronger in preresonance conditions with the $Q_{y}$ electronic transition than in resonance conditions with the Soret electronic transition of 2-vinyl-BChl $a$. The fact that this band disappears when the vinyl group is removed from the $\mathrm{Chl} a$ molecules, and the fact that adding a vinyl group to $\mathrm{BChl} a$ results in the presence of such a $1624 \mathrm{~cm}^{-1}$ band, lead to the conclusion that this mode does arise from the stretching frequency of the viny! substituent at the $\mathrm{C}-2$ position on the chlorin ring. Extensive Raman studies of the vinyl group in various organic compounds ${ }^{22}$ and in metal porphyrins $^{6,15,23,24}$ have provided precise wavenumber ranges for the Raman-active modes of this group.

Depending on the amount of conjugation and of vibrational coupling, specific Raman-active modes of porphyrin-bound vinyl groups are expected in the ranges $1610-1650 \mathrm{~cm}^{-1}\left(v \mathrm{C}_{2 \mathrm{a}}=\mathrm{C}_{2 \mathrm{~b}}\right), 1410-1440 \mathrm{~cm}^{-1}$ (= $=\mathrm{CH}_{2}$ symmetric scissoring), $1300-1310 \mathrm{~cm}^{-1}(=\mathrm{CH}$ rock) and $1070-1090 \mathrm{~cm}^{-1}\left(=\mathrm{CH}_{2}\right.$ rock $)$. Hence the $1624 \mathrm{~cm}^{-1}$ extra bands observed in RR spectra of $\mathrm{Chl} a$ and 2-vinyl-BChl $a$ are very likely to involve appreciably the $v \mathrm{C}_{2 \mathrm{a}}=\mathrm{C}_{2 \mathrm{~b}}$ coordinate. We further inspected the present spectra for the possible activity of a vinyl $\mathrm{CH}_{2}$ scissoring mode in the $1410-1440 \mathrm{~cm}^{-1}$ range, bearing in mind that in preresonance conditions at least, the $1624 \mathrm{~cm}^{-1}$ band is expected to be stronger than any other vinyl band. ${ }^{22}$ 
Figures 4 and 5 display the RR spectra of Chl $a$ and 2-acetyl-Chl $a$ with 1064 and $441.6 \mathrm{~nm}$ excitation, respectively. These spectra exhibit many relative intensity differences and wavenumber shifts. A weak 1327 $\mathrm{cm}^{-1}$ band is present in Chl a spectra excited at 1064 $\mathrm{nm}$ which might arise from the vinyl $\mathrm{CH}_{2}$ scissoring mode. This band is missing in the spectra of 2-acetylChl a. However, in the RR spectra of nickel methylpheophorbide, the band which has been attributed to the vinyl scissoring mode is weak in resonance conditions with the Soret electronic transition (i.e. in resonance with the $B$ state) and is clearly observable only in resonance conditions with the $Q_{y}$ transition. ${ }^{6}$ In the case of $\mathrm{Chl} a$, the $1325 \mathrm{~cm}^{-1}$ band is intense in resonance at $441.6 \mathrm{~nm}$, i.e. in resonance with the $B$ state (Fig. 5). It is worth noting that, on replacing the vinyl group with an acetyl at the $\mathrm{C}-2$ position on the chlorophyll macrocycle, many other perturbations of the RR spectra are observed, which probably result only indirectly from the presence of vinyl and/or acetyl groups, and thus cannot be safely used for diagnosing the chemical structure of a molecule. This is true, in particular, when comparing BChl $a$ and 2-vinyl-BChl $a$ (see Figs 6 and 7): the RR spectra of these two molecules differ in many spectral regions, but no band other than the $1625 \mathrm{~cm}^{-1}$ band can be safely attributed to vinyl contributions.

In resonance with the $B$ transition, the presence of an acetyl group as a substituent at the $\mathrm{C}-2$ position on the (B)Chl macrocycle appears to enhance a $c a .1070 \mathrm{~cm}^{-1}$ band. The RR spectra of 2-acetyl-Chl $a$ contain an intense band at $1068 \mathrm{~cm}^{-1}$ which is very weak in the RR spectra of Chl $a$ molecules (Fig. 5). A similar band is observed at $1072 \mathrm{~cm}^{-1}$ in the RR spectra of BChl $a$ molecules and is absent in those of 2-vinyl-BChl $a$ (Fig. 7). For BChl $a$ molcules, this mode has been reported to be sensitive to ${ }^{14} \mathrm{~N} /{ }^{15} \mathrm{~N}$ isotope substitutions in BChl $a$ (it shifts by $7 \mathrm{~cm}^{-1}$ ) and has accordingly been attributed mainly to $\mathrm{CN}$ contributions. ${ }^{4}$ Similarly, a band was observed at $1071 \mathrm{~cm}^{-1}$ in the RR spectra of nickel deuteroporphyrins possessing acetyl carbonyl groups at either in the C-2 or C-4 position, ${ }^{25}$ it had no counterpart in the RR spectra of formyl nickel deutero-

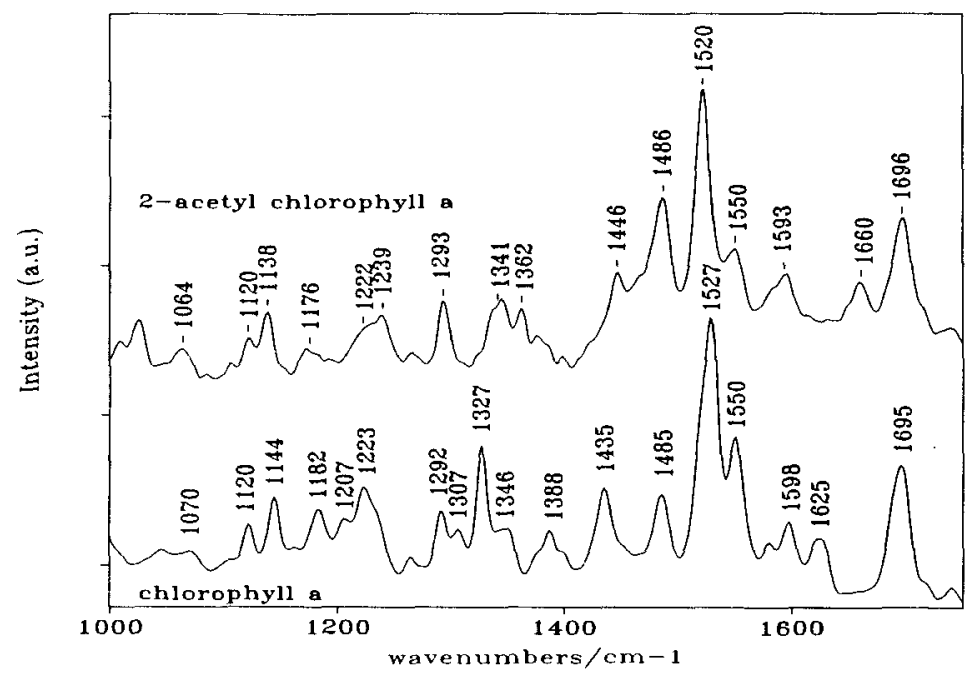

Figure 4. RR spectra of $\mathrm{Chl} a$ and 2 -acetyl- $\mathrm{Chl} a$ in THF $\left(1000-1750 \mathrm{~cm}^{-1}\right.$ range). Excitation at $1064 \mathrm{~nm}$; samples at room temperature.

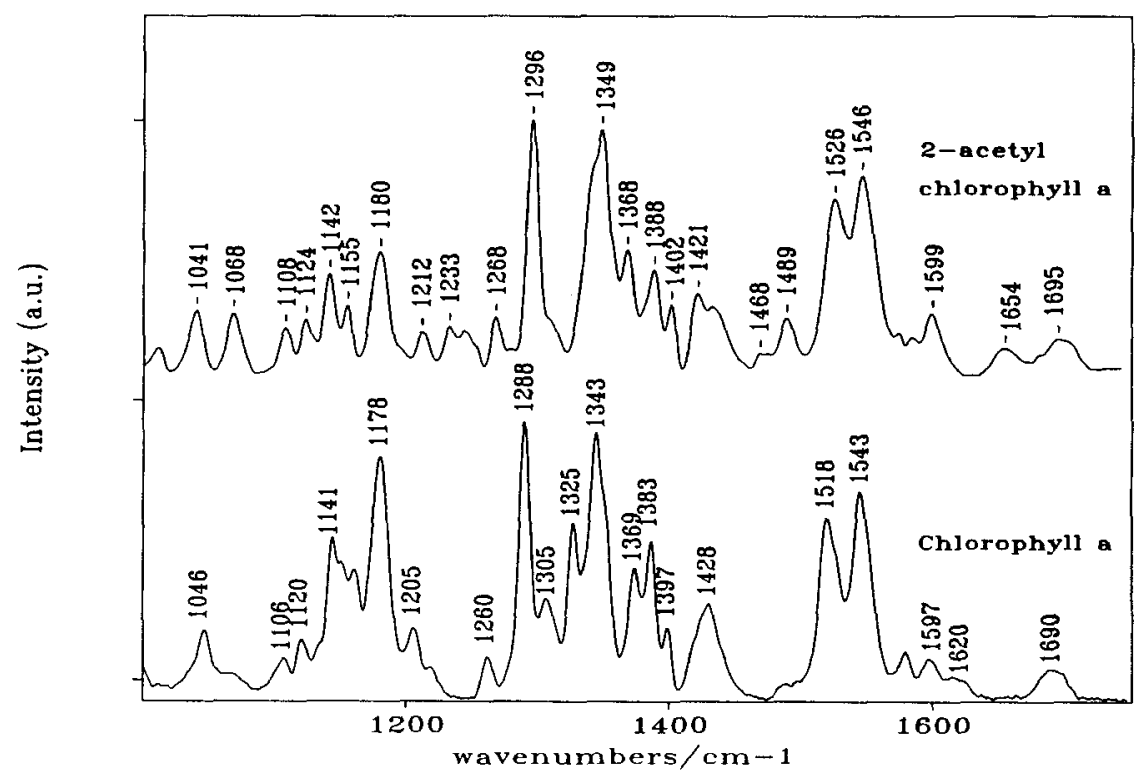

Figure 5. RR spectra of $\mathrm{Chl} a$ and 2-acetyl-Chl $a$ in THF $\left(1000-1750 \mathrm{~cm}^{-1}\right.$ range). Excitation at $441.6 \mathrm{~nm}$; samples at $77 \mathrm{~K}$. 


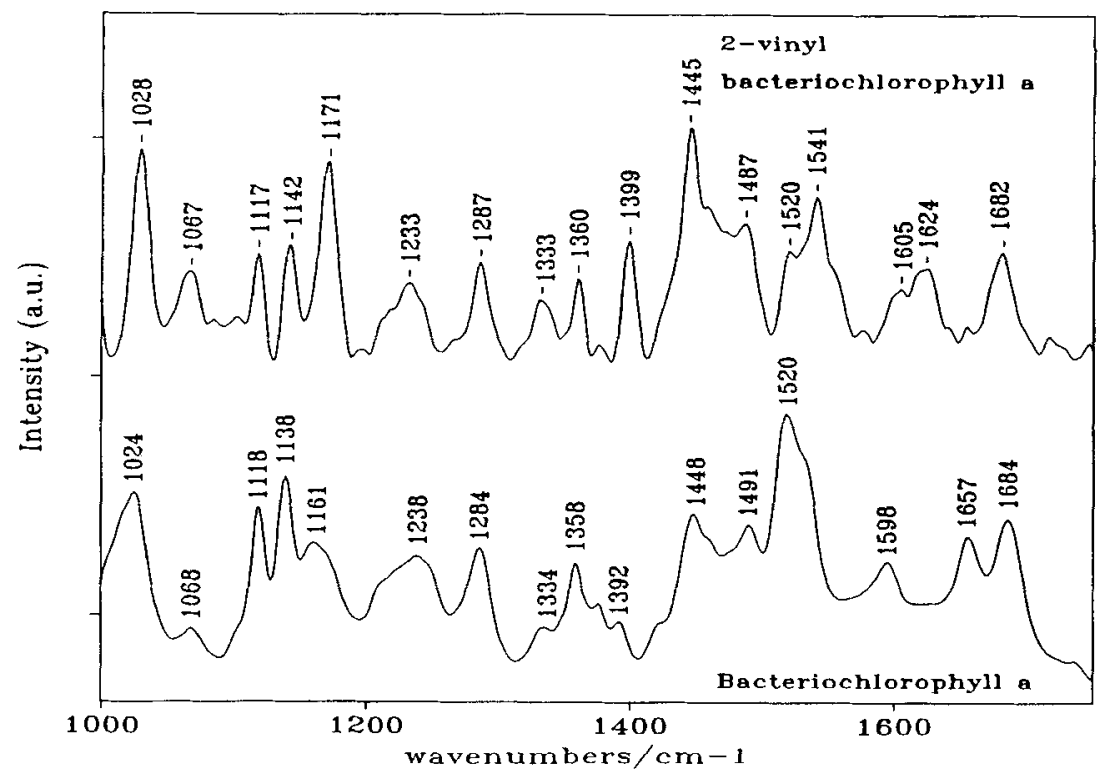

Figure 6. RR spectra of $\mathrm{BChl} a$ and 2-vinyl-BChl $a$ in THF (1000-1750 $\mathrm{cm}^{-1}$ range). Excitation at $1064 \mathrm{~nm}$; samples at room temperature.

porphyrins and of deuteroporphyrin. However, the frequency of these bands does not match with any characteristic frequency expected for in-plane acetyl modes. ${ }^{25}$ Despite this fact, RR data now available on four acetylsubstituted porphyrin derivatives suggest that a 1070 $\mathrm{cm}^{-1}$ band in the $R \mathbf{R}$ spectra may constitute a reliable marker for this substituent.

In summary, the absence of observable bands in the $1620-1660 \mathrm{~cm}^{-1}$ region of the RR spectra of $\mathrm{BChl} a$ and 2-acetyl-Chl $a$, at resonance either with the $B$ states or with the $Q_{y}$ state, indicates that no mode predominantly involving the $\mathrm{rC}_{\mathrm{a}} \mathrm{C}_{\mathrm{m}}$ coordinates should occur at wavenumbers higher than $1615 \mathrm{~cm}^{-1}$. The $1625 \mathrm{~cm}^{-1}$ band of the vinyl-containing compounds should not itself involve these coordinates as it is insensitive to $\mathrm{Mg}$ coordination (see below and Ref. 26). It therefore appears clear that, in the R R spectra of $\mathrm{BChl} a$, the presence of a band in the 1620-1660 wavenumber region is likely to indicate the presence of hydrogenbonded acetylcarbonyls in the sample considered.

On the other hand, this study has demonstrated that a mode predominantly involving the vinyl $\mathrm{C}=\mathrm{C}$ stretching coordinate is present in the RR spectra of $\mathrm{Chl}$ $a$. This band is more clearly observed in spectra excited in preresonance conditions, at $1064 \mathrm{~nm}$, from Chl $a$ samples in which the $\mathrm{Mg}$ is hexacoordinated rather than pentacoordinated. Indeed, in the RR spectra of chlorophylls with a pentacoordinated $\mathrm{Mg}$ atom, the $v \mathrm{C}_{\mathrm{a}} \mathrm{C}_{\mathrm{m}}$ band occurs around $1610 \mathrm{~cm}^{-1,4,12,13}$ and not around $1595 \mathrm{~cm}^{-1}$ as in hexacoordinated samples. In these conditions, the vinyl $v \mathrm{C}=\mathrm{C}$ band still occurs close to $1624 \mathrm{~cm}^{-1}$, and hence is only observed as a weak

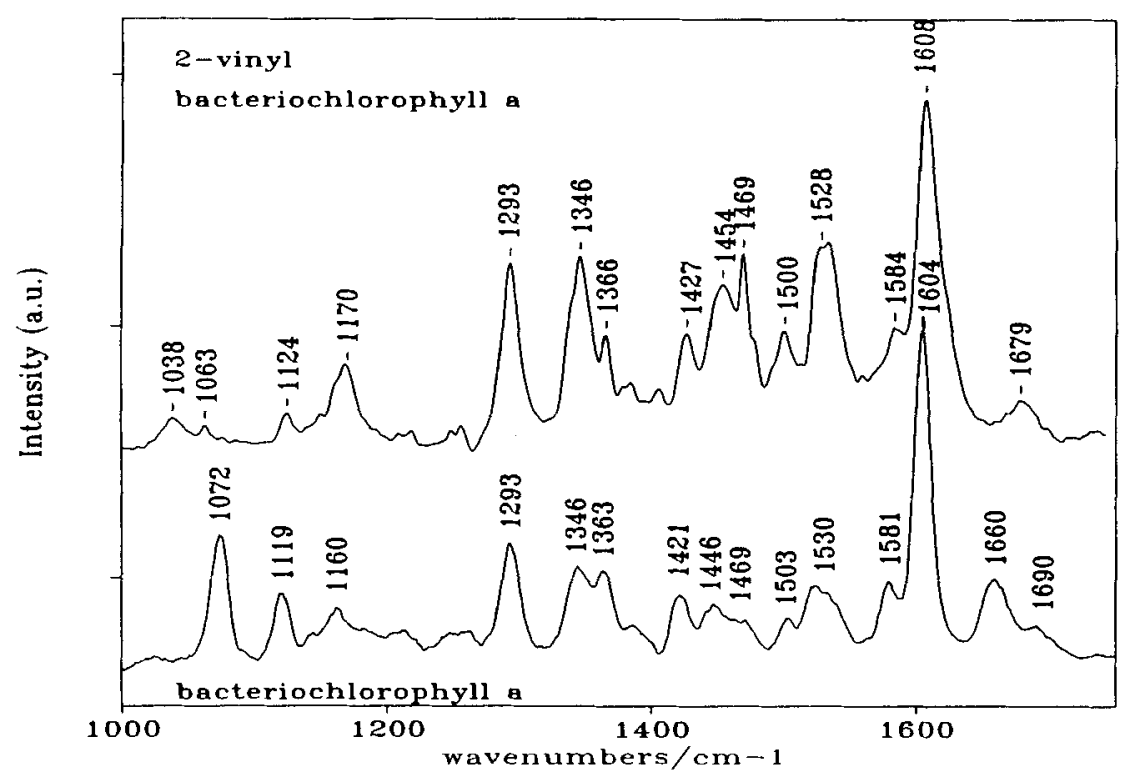

Figure 7. RR spectra of $\mathrm{BChl} a$ and 2-vinyl-BChl $a$ in THF (1000-1750 $\mathrm{cm}^{-1}$ range). Excitation at $363.8 \mathrm{~nm}$; samples at $77 \mathrm{~K}$. 
shoulder on the $v \mathrm{C}_{\mathrm{a}} \mathrm{C}_{\mathrm{m}}$ band. ${ }^{26}$ This is the reason why this mode may be difficult to see in proteins as the central $\mathrm{Mg}$ atom of $\mathrm{Chl} a$ is usually pentacoordinated in vivo. Through analysis of the $v \mathrm{C}_{\mathrm{a}} \mathrm{C}_{\mathrm{m}}$ bandshape, however, it may be identified in the RR spectra of pentacoordinated samples and in any resonance conditions including the Soret transitions. This mode may therefore safely be used for distinguishing $\mathrm{Chl}$ a-type cofac- tors from other chlorophylls such as $\mathrm{BChl} c$ which do not contain vinyl substituents. ${ }^{26}$

\section{Acknowledgements}

U.F. was supported by the EEC (Science Programme).

\section{REFERENCES}

1. J. Deisenhofer and H. Michel, EMBO J. 8, 47 (1989).

2. B. W. Matthews, R. E. Fenna, M. C. Bolognese, M. F. Schmid and J. M. Olson, J. Mol. Biol. 131, 259 (1979).

3. W. Kühlbrandt and D. N. Wang, Nature 350, 130 (1991).

4. M. Lutz and B. Robert, in Biological Applications of Raman Spectroscopy, edited by T. G. Spiro, Vol. 3, p. 347. WileyInterscience, New York (1988).

5. B. Robert, Biochem. Biophys. Acta 1017, 99 (1990).

6. N. J. Boldt, R. J. Donohoe, R. R. Birge and D. F. Bocian, J. Am. Chem. Soc. 109, 2284 (1987).

7. R. J. Donohoe, H. A. Frank and D. F. Bocian, Photochem. Photobiol. 48, 531 (1988).

8. M. Lutz, Biochim. Biophys. Acta 460, 408 (1977).

9. M. Lutz, Thesis, Université Pierre et Marie Curie, Paris (1979).

10. M. Fujiwara, H. Hayashi and M. Tasumi, Croati. Chemi. Acta 61, 435 (1988)

11. M. Lutz, J. Raman Spectrosc. 2, 497 (1974).

12. M. Fujiwara and M. Tasumi, J. Phys. Chem. 90, 250 (1986).

13. T. M. Cotton and R. P. van Duyne, J. Am. Chem. Soc. 103 , 6020.

14. T. A. Mattioli, A. Hoffmann, B. Robert, B. Schrader and M. Lutz, Biochemistry 30, 4648 (1991).

15. M. Lutz, and J. Kleo, C. R. Acad. Sci. 279, 1413 (1974).
16. S. Choi, T. G. Spiro, K. C. Langry, K. M. Smith, D. L. Budd and G. N. LaMar, J. Am. Chem. Soc. 104, 4345 (1982).

17. M. S. Fischer, D. H. Templeton, A. Zelkin and M. Calvin, J. Am. Chem. Soc. 94, 3613 (1972).

18. M. Lutz, in Advances in Infrared and Raman Spectroscopy, edited by R. J. H. Clarke and R. E. Hester, Vol. 11, Chapt. 5, p. 211. Wiley-Heyden, Chichester (1984).

19. J. R. L. Smith and M. Calvin, J. Am. Chem. Soc. 88, 4500 (1966).

20. A. Stuck, E. Cmiel, I. Katheder, W. Schäfer and H. Scheer, Biochim. Biophys. Acta 1101, 321 (1992).

21. B. Robert and M. Lutz, Biochemistry 25, 2302 (1986).

22. W. G. Fateley, G. L. Carlson and F. E. Dickson, Appl. Spectrosc. 22, 650 (1968).

23. S. Choi, T. G. Spiro, K. C. Langry and K. M. Smith, J. Am. Chem. Soc. 104, 4337 (1982).

24. H. Lee, M. Abe, R. K. Pandey, H.-K. Leung, K. M. Smith and T. Kitagawa, J. Mol. Struct. 146, 329 (1986).

25. D. L. Willems and D. F. Bocian, J. Am. Chem. Soc. 106, 880 (1984).

26. U. Feiler, C. Pourcet, T. A. Mattioli, M. Lutz and B. Robert Biochemistry submitted for publication. 